\title{
Reconocimiento de las materias primas líticas del sitio arqueológico La Cueva de Yavi (Jujuy)
}

Julio José Kulemeyer ${ }^{1}$ y Fernando Luis LóPeZ ${ }^{2}$

\section{RESUMEN}

Se estudia la petrografía y proveniencia de las materias primas líticas del sitio arqueológico La Cueva (Yavi, Jujuy, Argentina), a través de 26 cortes delgados. Se determinó la existencia de areniscas, limolitas, calizas reemplazadas por sílice y óxido férrico y vidrio teletermal. Todas las variedades litológicas pudieron relacionarse, en cuanto a su proveniencia más probable, con formaciones geológicas y afloramientos muy próximos al sitio La Cueva.

\begin{abstract}
Petrography and origin of lithic raw materials of the archaeological site "La Cueva" (Yavi, Province of Jujuy, Argentine) have been studied through 26 thin cuts. The existence of sandstone, limolites, telethermal glass and limestone replaced by silex and iron oxide has been proved. All the lithological varieties are related, as their most probable provenance, with neighbor geological formations and outcrops.
\end{abstract}

\section{Introducción}

La zona de estudio se encuentra en los alrededores del sitio arqueológico La Cueva $\left(22^{\circ} 08^{\prime}\right.$ Lat $\mathrm{S} ; 64^{\circ}$ 28' Long O), ubicado $300 \mathrm{~m}$ al norte de la localidad de Yavi, a 3412 m.snm. En su orografía sólo se destaca el Cerro Largo, extremo norte del Cordón de Siete Hermanos. La red hídrica, que drena al Atlántico, se compone de tres quebradas (Lecho-San José, Casti y Cajas-Yavi Chico) que se extienden de este a oeste desde la Sierra de Santa Victoria y que desembocan en el río Yavi.

El presente trabajo se basa en el análisis de 26 cortes delgados petrográficos, correspondientes a igual número de elementos arqueológicos en roca obtenidos de las excavaciones del sitio La Cueva,

1 Grupo Yavi, Casilla de Correo 78, (4600) Jujuy, ARGENTINA.

2 Facultad de Ciencias Naturales, Universidad Nacional de Tucumán. Miguel Lillo 105, (4000) Tucumán, ARGENTINA. los que incluían 24 artefactos y sólo dos rodados (muestras 14 y 23) como así también en la información geológica obtenida a lo largo de numerosas campañas desarrolladas a partir del año 1987.

El conocimiento de los tipos de materia prima lítica y de los afloramientos de proveniencia de las mismas, ayudará a comprender en detalle aspectos importantes relacionados a las costumbres y actividades de los hombres prehistóricos que habitaron la región. Por otra parte, algunos de los materiales que son objeto de estudio muy probablemente son excluidos de los afloramientos del área de Yavi, por lo que su aparición en otros sitios arqueológicos de la región puede considerarse como proveniente de las "canteras" de las inmediaciones de La Cueva, algunas de las cuales fueron reconocidas por J.A. Kulemeyer (1990).

El estudio litológico detallado permitirá obtener nuevas guías estratigráficas en los estudios arqueológicos, que se manifestarán por el aumento, predominio o desaparición de determinados materiales o asociaciones de los mismos, dando importante información acerca de las distancias recorridas por estos materiales y las preferencias que tuvieron, en la selección de materias primas los cazadores prehistóricos. Lynch y Stevenson (1992) analizaron en la región de Punta Negra la composición en elementos trazas y mediante cortes delgados materiales arqueológicos en obsidiana como uno de los pasos necesarios para la realización de dataciones por el método de hidratación de la obsidiana, observando en algunos casos la correlación directa entre los dos tipos de análisis y entre éstos y las observaciones macroscópicas. Por otra parte, constituye la base indispensable para estudios sobre efectos de la combustión (intencional o no) en el material lítico y las variaciones de dicha práctica en la secuencia de un yacimiento dado, tal como lo observaron Masson y colaboradores. (1980) en Longetraye (Haute-Loire) o conjuntos de yacimientos pertenecientes a uno o más períodos culturales, como es el caso de la región de Florida (Ste. Claire 1987). 


\section{Metodología}

Se seleccionaron 26 muestras de líticos provenientes de las excavaciones del sitio La Cueva, que a simple vista representaban a la gran mayoría de variedades litológicas de sitio, de las cuales 24 eran artefactos (lascas) y sólo dos, las muestras 14 y 23 , eran rodados sin evidencias de trabajo por el hombre, pero que, a juzgar por el contexto geológico y arqueológico del sitio su presencia está ligada a la actividad antrópica. De cada uno de los fragmentos de roca se extrajo una parte que fue utilizada en la confección de cortes delgados petrográficos, mientras que la parte restante fue montada en forma de muestrario; ambos materiales serán utilizados como material de referencia para cotejar con los restantes materiales arqueológicos de La Cueva y la región. Los cortes delgados y sus correspondientes muestras macroscópicas fueron numeradas en forma correlativa al azar, tal como aparecen en esta contribución.

Posteriormente, se analizó el contexto geológico local con el apoyo de cartografía levantada en trabajos anteriores (J. J. Kulemeyer 1988; J. A. Kulemeyer, y J. J. Kulemeyer 1989; J. J. Kulemeyer 1990); observaciones de los autores y las investigaciones arqueológicas que se realizan en forma interdisciplinaria (Kulemeyer et al. 1989; J. A. Kulemeyer 1990) permitieron delimitar los afloramientos que fueron explotados en épocas prehistóricas (Figura 1).

Finalmente, del análisis de los cortes delgados de La Cueva, como así también de otros correspondientes a las diversas formaciones geológicas de la zona (tales como los descritos por Turner 1964; Salfity 1980; Palma 1984 y otros) y la información geológica y arqueológica adicional con que se cuenta, se relaciona las materias primas con tipos litológicos y formaciones geológicas, para luego determinar tentativamente la proveniencia del material.

\section{Breve reseña arqueológica del área}

La zona Yavi, en especial en las inmediaciones de La Cueva, presenta una excepcional riqueza arqueológica, tanto en superficie como en estratigrafía (a cielo abierto y en abrigos) y cuyo registro cubre épocas precerámicas, acerámicas, cerámicas, de la época colonial y de formación actual (J. A. Kulemeyer, y J. J. Kulemeyer 1989; J. A. Kulemeyer 1990; J. J. Kulemeyer 1990).
El sitio La Cueva fue objeto de cuatro campañas de excavaciones arqueológicas: las dos primeras (1980 y 1981) fueron dirigidas por Krapovickas, en tanto que las restantes fueron llevadas a cabo por J.A. Kulemeyer. De los niveles inferiores se dataron por $\mathrm{C}^{14}$ dos muestras de carbón de fogón en $9480 \pm 220$ y $9760 \pm 160$ (Krapovickas 1987-88), en tanto que Kulemeyer y colaboradores (1989) asignan el sitio a épocas precerámicas (época en la que no existe la cerámica en la región) y acerámicas (momento en el que, si bien se tienen evidencias de que la cerámica era conocida en la región, fue poco o nada utilizada en el sitio arqueológico). En las excavaciones que realizara Kulemeyer se distinguieron 12 estratos sedimentarios, designados con letras mayúsculas desde la A (base) a la L (techo); en los mismos se ha considerado tentativamente al A como estéril, del B al I como precerámicos y los estratos J, K y L como acerámicos. Una de las características salientes del sitio es la gran abundancia de material lítico (fueron mapeadas aproximadamente 10000 piezas, predominantemente lascas en una superficie de $4 \mathrm{~m}$ cuadrados y una profundidad promedio de $85 \mathrm{~cm}$ ) y la variedad de materias primas allí observadas. Asimismo, se extrajo gran cantidad de restos óseos humanos y animales, cuentas de collar en hueso y sólo un fragmento cerámico. Entre las estructuras observadas, se destacan un gran fogón (capas E, F y G) y alineaciones curvas de rocas y carnadas de vegetales, asociadas a enterratorios. Las capas $\mathrm{K}$ y $\mathrm{L}$ representan a los niveles recientes en los que se encuentra escaso material lítico asociado a restos de vidrio de botella, tapas de gaseosa, etc. (Kulemeyer y Laguna, com. pers.).

En las inmediaciones se encuentra en superficie gran cantidad de material lítico, especialmente en las cercanías del denominado Perfil 2 (J. A. Kulemeyer, 1990) y en La Loma (en especial sobre los afloramientos de la Formación Yacoraite y en cercanías de la misma); en ambos casos los artefactos tienen, predominantemente, una composición petrográfica similar a la del sustrato rocoso sobre el que se hallan dispersos, lo que sumado a otros elementos de análisis permitió definir al lugar como talleres de talla de material lílico, con escasa perturbación desde su abandono (J. J. Kulemeyer 1990).

\section{Breve reseña geológica del área}

La zona estudiada (ver Figura 1) se encuentra en el borde oriental de la Puna y se caracteriza por una secuencia sedimentaria que comprende a la 

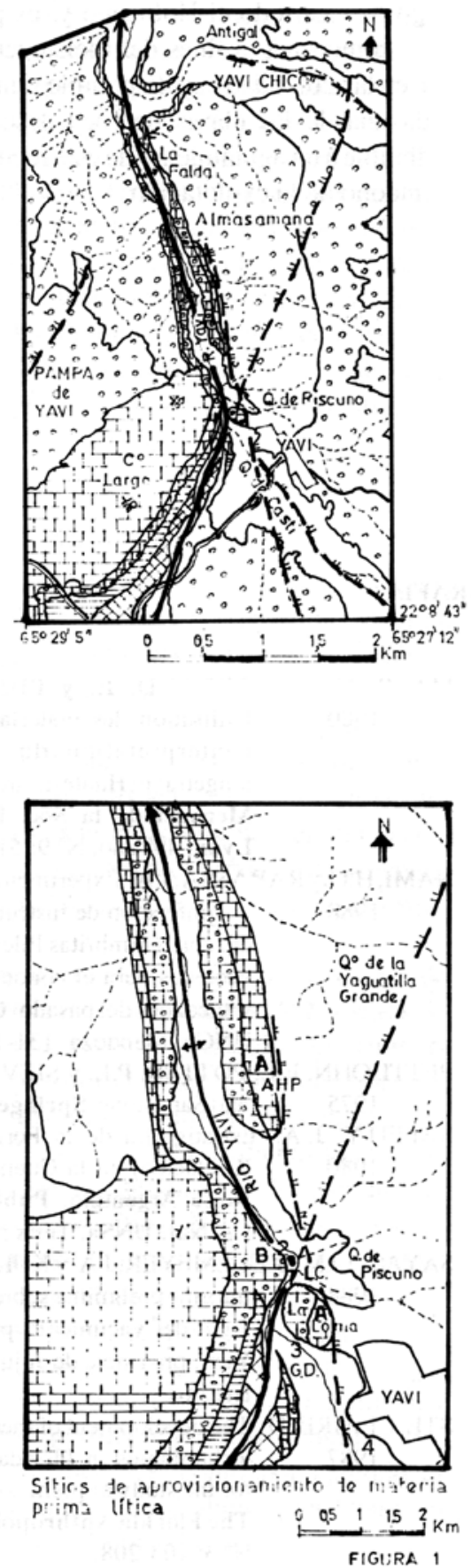

CUADRO ESTRATIGRAFICO

$\square$ Pleistoceno Tardio - Holoceno

?:: Plio-Pleistoceno

U.m. InIm Fealla

F. Yacoraite

Fing Lecho

F. Les Blanquitos

Eis F. Acoite

E STRUCTURAS

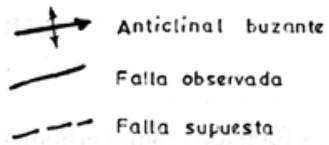

SITIOS DE APROVISIONAMIENTO DE MATERIAS PRIMAS

A - Vidrio teletermal y calizas reemplazadas

(Formación Yacoraite)

B - Areniscas (Formación Lecho)

SITIOS ARQUEOLOGICOS

2 Perfil 2

L.C. L.a Cueva

A.H.P. Alera de Hornopunta

G. D. Garganta del Diablo (EI Angosto)

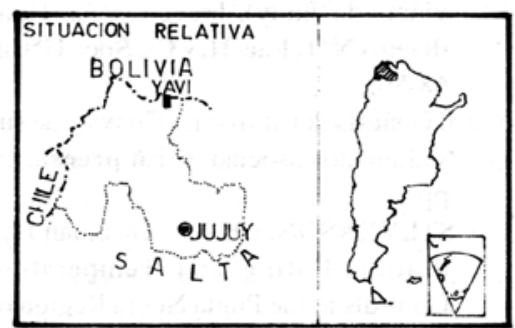

Dibujo Silvia S. Soliz

Figura 1. Mapa geológico de Yavi, Yavi Chico, Jujuy. 
Formación Acoite (Ordovícico), el Grupo Salta, que en la localidad está presente con las formaciones Los Blanquitos, Lecho, Yacoraite y Mealla (Cretácico Superior-Terciario Inferior); una secuencia fluviolacustre (Plio-Pleistoceno Inferior) y una secuencia de ciénagos y fluvial, portadora de restos arqueológicos y faunísticos interestratificados (Pleistoceno Tardío-Holoceno).

La estructura visible más importante es un anticlinal asimétrico (que está compuesto por la Formación Acoite y el Grupo Salta y constituye el Cordón de los Siete Hermanos) que presenta una falla en su plano axial que coincide con el cauce del río Yavi. Las sedimentitas de edad Plioceno SuperiorPleistoceno Inferior se depositaron en una cuenca que se extendió tanto al naciente como al poniente del mencionado cordón. Finalmente, constituye el relleno de los principales cauces fluviales actuales la secuencia Pleistoceno Tardío-Holoceno.

El sitio La Cueva se encuentra ubicado en el pequeño promontorio rocoso denominado La Loma, en rocas de la Formación Lecho. Estas se encuentran intensamente diaclasadas y meteorizadas por lo que se caracterizan por ser friables. Apoya sobre la misma la Formación Yacoraite, que en el lugar se caracteriza por haber sido totalmente reemplazada por sílice (principalmente) y óxidos de hierro y por estar atravesada por vetas de hasta $3 \mathrm{~cm}$ de espesor de vidrio teletermal (Figura 2), por lo que hemos podido reconocer al lugar como sitio de aprovisionamiento de materias primas (sólo para el vidrio y las rocas de la Formación Yacoraite). La Loma constituye parte del flanco oriental del anticlinal asimétrico, cuyo flanco occidental, mejor representado, corresponde al Cordón de Siete Hermanos. Los afloramientos del flanco oriental continúan en la margen derecha del río Yavi y hasta las inmediaciones de la quebrada de Yeguatilla Grande se mantienen las características apuntadas (es decir, que la Formación Lecho se presenta diaclasada y friable, la Formación Yacoraite reemplazada y atravesada por vetas de vidrio teletermal y las evidencias de la existencia de talleres). Es importante señalar que la presencia de vidrio hidrotermal está ligada a una falla (ver Figura 1) y por lo tanto la mineralización se restringe a las inmediaciones de la misma.

Otro sitio de aprovisionamiento con evidencias de talla y gran cantidad de material en superficie se halla en la margen izquierda del río Yavi, en afloramientos de areniscas de color gris y caramelo de la Formación Lecho. Se trata de rocas masivas, escasamente perturbadas y con evidencias menores de mineralización hidrotermal con las que se confeccionaron los numerosos artefactos del Perfil 2 (Sayago et al. 1988Ms; J. A. Kulemeyer 1990).

Aunque es poco frecuente en el sitio La Cueva, en la zona, más precisamente en las inmediaciones del caserío de Casti, en secuencias estratificadas de las márgenes del río homónimo, se hallaron lascas elaboradas sobre rodados de cuarzoarenitas pertenecientes al Grupo Mesón. La explotación de estos rodados tiene una distribución regional muy importante (debido a la gran extensión areal de los afloramientos del grupo), ya que se continúan encontrando en localidades distantes a $350 \mathrm{~km}$, como San Pedro de Jujuy, como así también en San Salvador de Jujuy y localidades vecinas, aunque al presente no se conoce una ubicación temporal para la explotación de dicha materia prima.

\section{Edad y calidad de los materiales estudiados}

Debido a que provienen de diversos niveles arqueológicos del sitio La Cueva, se asigna al conjunto de los materiales estudiados a épocas precerámicas y acerámicas, en concordancia con la edad del sitio. Debe aclararse que en la excavación de 1990 realizada por el equipo de Kulemeyer, se pudo observar en los niveles basales de la secuencia la presencia de variadas materias primas, que representan parcialmente al conjunto de las que se estudian en la presente contribución; es decir, que ya desde principios del Holoceno se conocía gran parte de los recursos pétreos utilizados luego, a lo largo de la historia ocupacional del sitio. Esto implicaría un conocimiento de los recursos naturales previo a la primera ocupación de La Cueva, por lo que, es probable, se encuentre en las inmediaciones evidencias más antiguas de la explotación del recurso y de la presencia humana. Idénticas características se mantienen en los niveles acerámicos, en los que se utilizaron diversas materias primas.

Un fragmento de roca proveniente de la Formación Yacoraite de La Loma, en el que predominaba la sílice sobre los óxidos de hierro, fue tallado experimentalmente por Nami, quien informó de las buenas propiedades para la talla del mismo (Nami com. pers.). Aplicando la escala nominal para clasificar las rocas útiles para fabricar instrumentos presentada por el mencionado investigador, podemos concluir que las rocas estudiadas, en general, son buenas, 


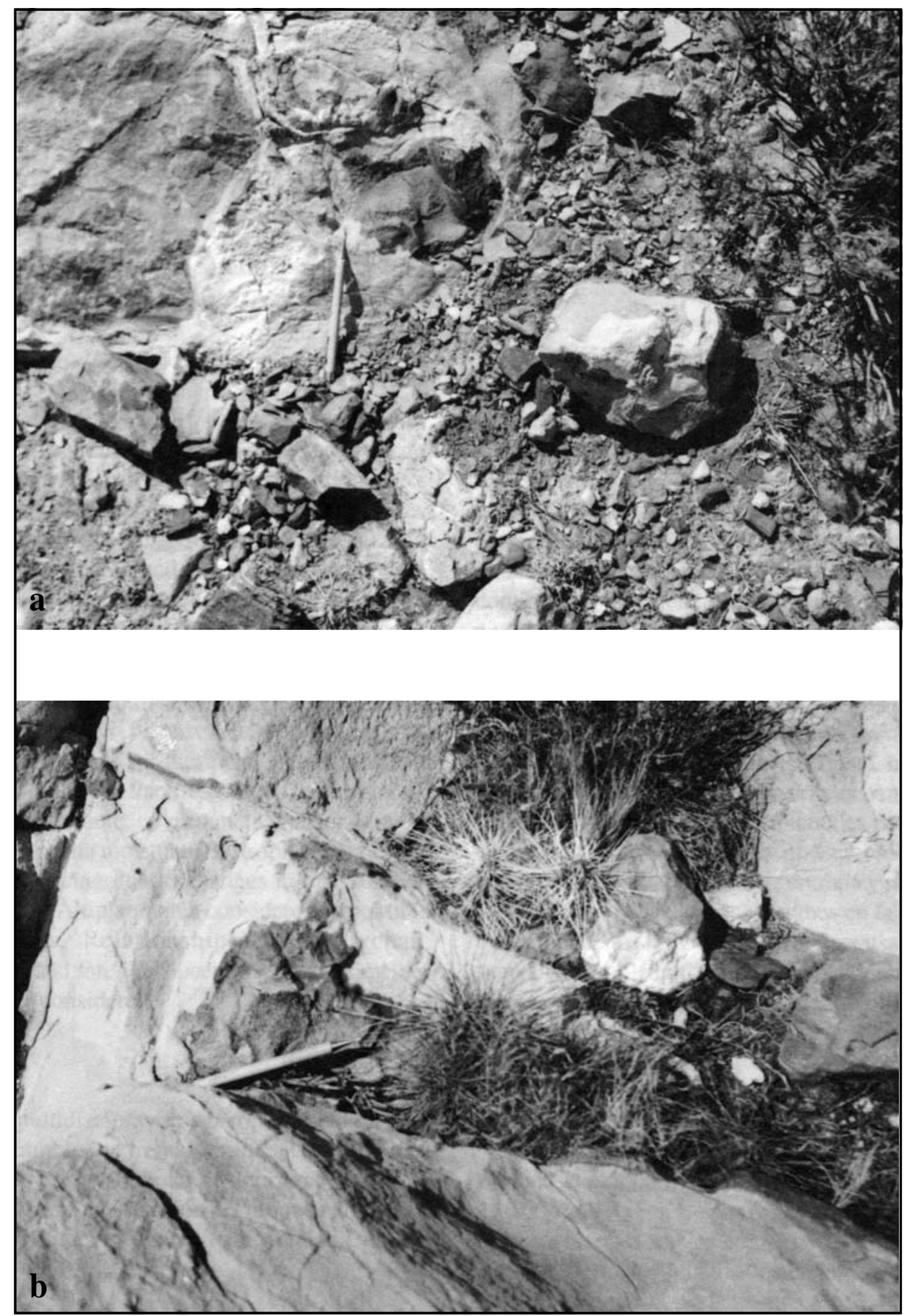

Figura 2. Calizas reemplazadas por sílice y óxidos de hierro con evidencias de explotación (negativos de lascado). Nótese que la mineralización se presenta en los planos de diaclasa de la roca, por donde circularan los fluidos hidrotermales. 
es decir que “...tienen todas las características que hacen que una roca sea codiciada o buscada por un tallador, pero con algunas falencias para emplear sobre ellas algunas técnicas y lograr ciertos fines" (Nami y Rabassa 1988). Los principales limitantes observados son los planos de diaclasa y las discontinuidades minerales en las rocas de la Formación Yacoraite, el tamaño de grano (arenisca mediana) en la Formación Lecho y el escaso espesor en las vetas teletermales.

\section{Descripción de los cortes delgados}

Al realizar la descripción de los cortes delgados se tuvo en cuenta aspectos genéticos que permitieron identificar más fácilmente la formación geológica y el afloramiento de proveniencia, basando la clasificación de las rocas en Marchese y Fernández (1967) y en Pettijohn y colaboradores (1975). Si bien hubiese sido correcto denominar como sílex o pedernales a ciertas rocas que fueron objeto de este estudio (las calizas en cuyo reemplazo predomina la sílice por el óxido de hierro), se ha preferido utilizar una denominación que permita remitirnos más fácilmente a la roca original (y con ello a la formación geológica de que proviene) evitando una división tajante con aquéllas en que predomina el reemplazo por óxidos de hierro.

Es oportuno agregar que los vidrios teletermales silíceos pueden ser considerados, tanto por su aspecto como por su composición como obsidianas, pero dicha denominación no es correcta ya que implica que genéticamente está ligada a lavas volcánicas, posibilidad que, en principio, se descarta.

En cuanto a los reemplazos, los órdenes en que se presentan implican un predominio de uno sobre el otro, como por ejemplo, en el primer corte tenemos una Waca lítica con reemplazo ferruginoso y silíceo, ello implica un predominio del reemplazo ferruginoso sobre el silíceo. Asimismo, debe aclararse que en las areniscas lo reemplazado es el cemento, en tanto que en las calizas es la totalidad de la roca, que aparentemente, por tratarse de un termalismo de baja temperatura, conserva en gran medida las estructuras primarias de la roca.

Corte 1. Waca lítica con reemplazo ferruginoso y silíceo, contiene $70 \%$ de cuarzo subequigranular, subredondeado a redondeado de aspecto límpido, aunque ocasionalmente se presentan granos fracturados y corroídos. Hay $3 \%$ de oolitas que sufrieron reemplazos por material silíceo y ferruginoso; cantidades menores de feldespato potásico, plagioclasa y $5 \%$ de líticos. El 20\% restante corresponde a óxidos de hierro y sílice, que constituyen un reemplazo del cemento original.

Corte 2. Sublitarenita con reemplazo ferruginoso y silíceo, constituida por $65 \%$ de cuarzo inequigranular, redondeado; los líticos representan $8 \%$ del corte y son de origen metamórfico; $2 \%$ de feldespato potásico y $5 \%$ de oolitas, en similares condiciones a las del corte 1 . En el cemento predomina el óxido de hierro sobre la sílice y, en general, los minerales se presentan con los contornos corroídos.

Corte 3. Oolita oligobiointraclástica con reemplazo ferruginoso y silíceo, las oolitas constituyen 50\% del corte, son de formas esféricas a subelípticas, con núcleos de minerales detríticos, fragmentos de oolitas o fósiles (bivalvos y ostrácodos) constituyen $15 \%$ del corte y se presentan frecuentemente fracturados; los intraclastos constituyen $5 \%$ del corte. Tanto las oolitas como los fósiles e intraclastos sufrieron reemplazos por sílice y óxidos de hierro, en tanto que el cemento (30\% restante) ha sido totalmente reemplazado por óxidos de hierro.

Corte 4. Oolita oligobiointraclástica con reemplazo silíceo y ferruginoso, constituida por $75 \%$ de oolitas de formas esféricas a subelípticas; $3 \%$ de fósiles; $2 \%$ de intraclastos y $2 \%$ de calcedonia plumosa. Debido al reemplazo silíceo y de óxidos de hierro, las estructuras originales de la roca desaparecieron parcialmente; asimismo, los constituyentes aparecen frecuentemente fracturados.

Corte 5. Oolita oligobiointraclástica con reemplazo silíceo y ferruginoso, constituido por $50 \%$ de oolilas esféricas y elípticas; $15 \%$ de fósiles; $10 \%$ de intraclastos y porcentajes menores de opacos, cuarzo y feldespato potásico. La sílice y el óxido de hierro constituyen el reemplazo en la totalidad de la roca.

Corte 6. Oolita oligobiointraclástica con reemplazo silíceo y ferruginoso, presenta $60 \%$ de oolitas esféricas y elípticas; $5 \%$ de fósiles (bivalvos y ostrácodos) y $2 \%$ de intraclastos. Todos ellos sufrieron un reemplazo total por sílice y óxido de hierro, en tanto que el cemento (33\%) ha sido reemplazado sólo por óxido de hierro. 
Corte 7. Oolita oligonodobioestromatolítica con reemplazo silíceo y ferruginoso, con $70 \%$ de oolitas elípticas a subesféricas, algunas fracturadas y cuyos núcleos están constituidos por líticos, fósiles o fragmentos de oolitas. Presenta escasos fósiles ( $1 \%)$; cuarzo (1\%), nodulos $(2 \%)$ y estromatolitos (1\%). La roca ha sido reemplazada por sílice y óxidos de hierro.

Corte 8. Fósiles oligointracuarzosos con reemplazo silíceo y ferruginoso, presenta $40 \%$ de fósiles (gastrópodos y bivalvos), 10\% de intraclastos y $2 \%$ de cuarzo límpido y raramente fracturado. La roca, en especial su cemento, fue reemplazado mayoritariamente por sílice, en tanto que los fósiles e intraclastos sufrieron reemplazos parciales por óxidos de hierro.

Corte 9. Oolita oligobiocuarzosa con reemplazo silíceo y ferruginoso, constituida por $75 \%$ de oolitas, $5 \%$ de fósiles y $2 \%$ de cuarzo en cristales pequeños y angulosos; el cemento constituye el 18\% de la roca. La misma sufrió un reemplazo total por sílice y óxidos de hierro.

Corte 10. Cuarzoarenita, constituida por $90 \%$ de cuarzo, en granos subredondeados a redondeados, que presentan extinciones paralela, fragmentosa y concéntrica; $3 \%$ de fragmentos líticos (cuarcita), $2 \%$ de microclino y $1 \%$ de circón. Los contactos son planos y cóncavos-convexos.

Corte 11. Oolita oligointraclástica con reemplazo silíceo y ferruginoso, presenta $60 \%$ de oolitas y menos de $10 \%$ de intraclastos; la parte restante del corte (30\%) corresponde al cemento. La roca ha sufrido un reemplazo total por sílice y óxidos de hierro.

Corte 12. Oolita oligobiointraclástica con reemplazo ferruginoso y silíceo, presenta $70 \%$ de oolitas, de forma predominantemente elíptica; 3\% de fósiles (bivalvos) y $2 \%$ de intraclastos. La roca ha sido reemplazada por óxidos de hierro y sílice.

Corte 13. Oolita con reemplazo ferruginoso y silíceo, las oolitas representan $75 \%$ de la roca, se presentan redondeadas y elípticas y sus núcleos están constituidos de fragmentos de fósiles y minerales detríticos. La roca ha sido reemplazada por óxidos de hierro y sílice.

Corte 14. Fangolita, constituida por $60 \%$ de cuarzo, el que se presenta anguloso a subanguloso, a veces con crecimiento secundario; además contiene cantidades menores de muscovita, plagioclasa, circón, opacos, biotita, líticos (cataclasitas y pasta de vulcanitas) y microclino, que totaliza $10 \%$. La textura es equigranular, a subequigranular, los contactos son flotantes, planos y cóncavos-convexos. Se observan bandeamientos determinados por concentraciones de óxido de hierro. El cemento (30\%) es de Calcita.

Corte 15. Vidrio tele termal ferruginoso y silíceo, caracterizado por un predominio de cristales y cemento de opacos (óxido de hierro), con venillas de sílice y algunos granos de cuarzo aislado. Los minerales suelen presentarse alineados.

Corte 16. Oolita oligointrafosilífera con reemplazo silíceo y ferruginoso, las oolilas representan $70 \%$ del corte, sus núcleos están constituidos por fósiles e intraclastos. Los intraclastos constituyen el 10\%. Se observa 5\% de fósiles (bivalvos y ostrácodos). El cemento representa $15 \%$ del corte. La roca sufrió un reemplazo total por sílice y óxidos de hierro.

Corte 17. Vidrio teletermal silíceo, en un sector del corte en contacto neto con el vidrio se observan granos de cuarzo aislados, angulosos (algunos aciculares), óxidos de hierro y liloclastos de arenisca. En la parte del corte en que predomina el vidrio se observan pequeños granos de cuarzo aislados y escaso óxido de hierro.

Corte 18. Cuarzoarenita, constituida por $98 \%$ de cuarzo, cuyo aspecto es límpido y que representa crecimiento secundario. La textura es subequigranular y los granos son subredondeados a subangulosos. Los contactos son planos, cóncavos-convexos y suturados; la extinción es paralela, fragmentosa y concéntrica. El restante $2 \%$ del corte está integrado por opacos.

Corte 19. Waca lítica con reemplazo ferruginoso, el cuarzo representa $70 \%$ de la roca y se presenta en granos redondeados a subredondeados, con el contorno corroído por óxidos de hierro; las oolitas, que representan $10 \%$, son radiales y concéntricas y sufrieron reemplazo por sílice y óxido de hierro. El cemento, $(15 \%)$ fue reemplazado por óxido de hierro.

Corte 20. Cuarzoarenita, presenta $95 \%$ de cuarzo en agregados policristalinos, los granos son subredondeados a subangulosos y la extinción es paralela y fragmentosa. Presenta una vena de cuarzo microcristalino y otra de calcedonia. Contiene además, 
escasa cantidad de muscovita, circón y feldespatos. Los contactos entre los granos son planos, cóncavoconvexos y suturados. Presenta escaso cemento de óxidos de hierro.

Corte 21. Vidrio teletermal silíceo, se trata de un vidrio silíceo con granos de cuarzo de extinción ondulosa y aspecto límpido dispersos, formando alineaciones, al igual que algunas globulitas. Asimismo, presenta granos aislados de circón.

Corte 22. Vidrio teletermal ferruginoso, con un alto contenido de opacos. Hay fenocristales de vidrio silíceo corroído. En total, las fenocristales representan $20 \%$ del corte y tienen una composición similar. No se observa una orientación especial en los constituyentes.

Corte 23. Limolita, la textura es microcristalina, equigranular. Los principales minerales son cuarzo (60\%), opacos (35\%) y muscovita (5\%). Los minerales presentan orientaciones preferenciales y en el corte se observan sectores con variaciones en el contenido de óxido ferroso. El mismo óxido rellena dos grietas que atraviesan el corte.

Corte 24. Vidrio teletermal silíceo, el vidrio constituye 95\% del corte y presenta, además, pequeños cristales prismáticos de cuarzo y opacos en alineación plano paralela y cantidades menores de circón, baculitos y escapulitas.

Corte 25. Oolita oligobioestromatolítica cuarzosa con reemplazo silíceo y ferruginoso, presenta $60 \%$ de oolilas (con núcleos constituidos por fósiles), $10 \%$ de fósiles (bivalvos, ostrácodos y cefalópodos) y $5 \%$ de estromatolilos. Se observan granos aislados de cuarzo $(1 \%)$ y venas de calcedonia (4\%). El cemento constituye el restante $20 \%$. La roca ha sufrido un reemplazo total por sílice y óxido de hierro.
Corte 26. Vidrio teletermal silíceo y ferruginoso, constituido mayormente por sílice, el vidrio representa $80 \%$ del corte. Se observan granos de cuarzo, opacos y fenocristales de vidrio silíceo angulosos y sin orientaciones preferenciales.

\section{Grandes grupos de materias primas}

Por su litología original, se clasifican en:

a) Areniscas (Cortes 1, 2, 10, 14, 18, 19, 20).

b) Calizas (Cortes 3, 4, 5, 6, 7, 8, 9, 11, 12, 13, $16,25)$.

c) Vidrios (Cortes 15, 17, 21, 22, 24, 26).

d) Limolita (Corte 23).

Por el reemplazo sufrido:

a) Ferruginoso (Cortes 19, 22).

b) Ferruginoso $>$ Silíceo (Cortes, 1, 2, 3, 12, 13, 15).

c) Silíceo > Ferruginoso (Cortes 4, 5, 6, 7, 8, 9, 11, $16,25,26)$.

d) Silíceo (Cortes 17, 21, 24).

e) Sin reemplazo (Cortes 10, 14, 18, 20, 23).

En esta última clasificación se debe hacer la salvedad que al vidrio, a pesar de ser el material original, se lo agrupó en las diversas divisiones arbitrarias del quimismo, para así tener una idea más clara sobre las preferencias en la selección de materiales de los hombres del pasado.

Combinando ambas clasificaciones, tendremos una idea global de qué tipos de rocas y con qué quimismo fueron utilizados preferencialmente en La Cueva (Cuadro 1).

Fue posible asignar tentativamente cada muestra a una formación geológica y relacionarla con el quimismo dominante (Cuadro 2).

\begin{tabular}{|l|c|c|c|c|c|}
\hline \multicolumn{1}{|l|}{ Reemplazo } & Ferruginoso & Ferr. > Silíceo & Silíceo $>$ Ferr. & Silíceo & Sin reemplazo \\
\hline Arsenitas & - & 1,2 & - & - & $10,14,18,20$ \\
\hline Limonitas & - & - & - & - & 23 \\
\hline Calizas & - & $3,12,13$ & $4,5,6,7,8,9,11,16,25$ & - & - \\
\hline Vidrios & 22 & 15 & 26 & $17,21,24$ & - \\
\hline
\end{tabular}

Cuadro 1. Rocas utilizadas en La Cueva. 


\begin{tabular}{|l|c|c|c|c|c|}
\hline \multicolumn{1}{|c|}{ Reemplazo } & Fermación & Ferr. > Silíceo & Silíceo $>$ Ferr. & Silíceo & Sin reemplazo \\
\hline Lecho & - & - & - & - & $10,18,20$ \\
\hline Yacoraite & 19 & $1,2,3,12,13$ & $4,5,6,7,8,9,11,16,25$ & - & - \\
\hline Los Blanquitos & - & - & - & - & 14 \\
\hline Vetas teletermales & 22 & 15 & 26 & $17,21,24$ & - \\
\hline Plio-Pleistoceno & - & - & - & - & 23 \\
\hline
\end{tabular}

Cuadro 2. Formaciones geológicas y quimismo dominante.

Del análisis de ambos cuadros surge que corresponden a la Formación Yacoraite todas las calizas (en casi todos los casos oolíticas) y algunas areniscas, caracterizándose el conjunto por presentarse siempre con diversos grados de reemplazos de óxidos de hierro y sílice, aunque generalmente predomina esta última. El quimismo del vidrio teletermal es variado, aunque nuevamente se encontraron más ejemplares con predominio silíceo. Las areniscas que se asignaron a la Formación Lecho son cuarzoarenitas sin ningún tipo de sustitución. Las muestras asignadas a las formaciones Acoite y Los Blanquitos no presentan reemplazos; debe tenerse en cuenta que ambas no constituyen materias primas para la confección de artefactos líticos, y que su presencia en el yacimiento, si bien se cree que está ligada a la actividad antrópica, aún no ha sido completamente explicada y son objeto de investigaciones en curso.

\section{Discusión}

El estudio de las materias primas de los artefactos líticos arqueológicos de La Cueva permite poner en relieve la importancia que adquiere el trabajo multidisciplinario entre las ciencias naturales y la arqueología. Llama la atención el escaso interés puesto en el estudio de materias primas líticas en el Noroeste Argentino, más aún si tenemos en cuenta que estos análisis son indispensables en el conocimiento preciso de importantes aspectos de la economía, comercio, hábitos, etc., de los hombres prehistóricos.

El emplazamiento de La Cueva y otros sitios de las inmediaciones a escasos metros de los sitios de explotación de materias primas adquiere gran importancia para reconstruir la historia de las explotaciones de dichas materias primas y, a la inversa, el conocimiento de la existencia de dichas fuentes de aprovisionamiento arroja luz sobre los estudios de funcionalidad de los sitios. No obstante, el gran volumen de material lítico arqueológico en superficie deberá ser cuidadosamente estudiado, ya que tiene una relativamente escasa perturbación.

Existe una gran cantidad de artefactos líticos arqueológicos en la superficie de los afloramientos, en tanto que en los perfiles holocenos de las inmediaciones (salvo excepciones, como por ejemplo el perfil 2), los artefactos no son abundantes (como en los perfiles 1, 6, la parte inferior del perfil 7 y el que se observa bajo el alero de Hornopunta). Además, se observan marcados localismos en la distribución de los artefactos líticos, lo que se refleja tanto en sitios de superficie como en los perfiles mencionados.

Es indudable que el conocimiento de dichas actividades permite conocer los efectos de la influencia antrópica en el registro sedimentario, especialmente en un área de intensa actividad humana a lo largo del Holoceno. Esto, a su vez, es indispensable para el conocimiento de los paleoclimas y paleoambientes de la zona y de la evolución de los mismos durante el Holoceno.

\section{Conclusiones}

Los materiales líticos hallados en el sitio La Cueva son areniscas, limolita, calizas y vidrio, con diversos grados de reemplazo por sílice y óxidos de hierro. Las areniscas se presentan sin reemplazo o con reemplazo predominantemente ferruginoso. Las calizas utilizadas en el sitio han sufrido un reemplazo total por sílice (mayoritariamente) y óxidos de hierro. En los vidrios se presenta la más amplia gama de quimismo, aunque la sílice es la más frecuente. $\mathrm{La}$ limolita no ha sufrido reemplazo, aunque presenta pequeñas venas de óxidos de hierro. 
Provienen de la Formación Yacoraite los cortes 1, 2, 3, 4, 5, 6, 7, 8, 9, 11, 12, 13, 16, 19 y 25; de la Formación Lecho provienen los cortes 10, 18 y 20; de la Formación Pirgua el corte 14: de las vetas teletermales que atraviesan a la Formación Yacoraite los cortes $15,17,21,22,24$ y 26 y de la secuencia fluvio lacustre de edad Plio-Pleistocena el corte 23.

Los sitios de explotación de las areniscas de la Formación Lecho se encuentran ubicados en la margen izquierda del río Yavi, en las inmediaciones del perfil 2 y hasta $200 \mathrm{~m}$ al oeste. La caliza con reemplazos silíceos y de óxidos de hierro y el vidrio teletermal se encuentran en los mismos afloramientos y están genéticamente relacionados. Ambos materiales fueron explotados en La Loma y en la prolongación norte de dicho afloramiento, hasta las inmediaciones de la quebrada de Yeguatilla Grande. La muestra 14 es un clasto de la Formación Los Blanquitos sin evidencias de trabajo antrópico, pero se tiene certeza de que fue transportado por el hombre y se obtuvo, muy probablemente, de los afloramientos de la quebrada de Lecho-San José. La muestra 23 es un rodado que caracteriza la parte media de la secuencia estratigráfica de La Cueva y proviene de conglomerados de edad Plio-Pleistoceno que apoyan en discordancia angular sobre la Formación Yacoraite tanto en $\mathrm{La}$
Loma como en los afloramientos que constituyen la prolongación norte de la misma, en la margen derecha del río Yavi, a su vez, la roca madre del conglomerado es, principalmente, la Formación Acoite. El modo de aporte de estos dos últimos tipos de rocas al sitio aún está en discusión, no descartándose la influencia antrópica.

De las diversas materias primas estudiadas en la presente contribución, es probable que los vidrios y las calizas reemplazadas (especialmente estas últimas) sean exclusivas de las inmediaciones de La Cueva; esto se debe a las condiciones geológicas particulares en que se originaron dichos materiales. En el caso de las cuarzoarenitas de la Formación Lecho no ocurre lo mismo, y teniendo en cuenta la amplia distribución de las mismas, es muy probable la existencia de numerosos sitios de aprovisionamiento en afloramientos de dicha formación en el Noroeste Argentino.

La explotación de estos materiales se dio a lo largo de casi todo el Holoceno y, es probable que haya comenzado a fines del Pleistoceno. Debido a que en la actualidad hay disponible gran cantidad de cada una de las clases de roca descritas, no es atribuible a un agotamiento de este recurso natural el abandono de la explotación.

\section{REFERENCIAS CITADAS}

KRAPOVICKAS, P., 1987-88. Nuevos fechados radiocarbónicos para el sector oriental de la Puna y la Quebrada de Humahuaca. Runa XVII-XVIII: 207-220.

KULEMEYER, J. A., 1990. Informe acerca de un material del Perfil 2 de Yavi, Jujuy. En prensa.

KULEMEYER, J. A. y J. J. KULEMEYER, 1989. Algunas consideraciones acerca de la geología y la arqueología del sistema del río Yavi (Depto. de Yavi, Provincia de Jujuy). Comunicaciones Científicas 1 (1).

KULEMEYER, J. A., L. R. LAGUNA y A. G. VIANA, 1989. Arqueología del sitio La Cueva y zonas aledañas (Departamento de Yavi, Provincia de Jujuy), breve reseña. Cuadernos 1: 68-80.

KULEMEYER, J. J., 1990. Génesis del abrigo La Cueva y de sus sedimentos asociados. En prensa.

LYNCH, T. y C. STEVENSON, 1992. Obsidian hydration dating and temperature controls in the Punta Negra Region of Northern Chile. Quaternary Research 37: 117-124.

MARCHESE, H. G. y C.A. FERNANDEZ, 1967. Clasificación petrográfica de sedimentitas carbonáticas. RAGA 22 (1): 80-95.
MASSON, A., E. DEBARD y D. PHILIBERT, 1980. Utilisation des materiaux brules dan l'interpretation du gisement de longetraye (Haute-Loire). Ex. du Bulletin Mensuel de la Societè Linnéenne de Lyon 49 (9): 516-521.

NAMI, H. C. y J. A. RABASSA, 1988. Experimentos, petrografía y confección de instrumentos de piedra con ignimbritas Pilcaniyeu. Observaciones para el conocimiento de las sociedades del pasado. CEIDER 2: 131-148, MHS.

PETTIJOHN, F. J., P. E. POTTER y R. SIEVER, 1975. Sand and sandstone. Springer Verlag.

SALFITY, J. A., 1980. Estratigrafía de la Formación Lecho (Cretácico) en la cuenca andina del norte argentino. Publicación especial del Departamento de Ciencias Naturales de la Universidad Nacional de Salta. Tesis 1.

SAYAGO, J. M., J. A. KULEMEYER y J. J. KULEMEYER, 1988Ms. Informe preliminar sobre la geoarqueología del yacimiento precerámico de Yavi, Provincia de Jujuy, Argentina.

STE. CLAIRE, D., 1987. The development of thermal alteration technologies in Florida: Implications for the study of prehistoric adaptation. The Florida Anthropologist 40 (3): 203-208. 